\title{
The Effect of Sports Experience and Competitive Orientation on Entrepreneurial Priorities, Attitudes, and Decision Making
}

\author{
Vedha Arikatla ${ }^{1}$ and Genevieve Gregorich\# \\ ${ }^{1}$ Vidyashilp Academy, Bangalore, KA, India \\ \#Advisor
}

$\underline{\text { ABSTRACT }}$

This paper poses a few questions about the link between athletic experience and entrepreneurial behavior. Does athletic experience affect entrepreneurial attitudes, decisions, and, therefore, outcomes? If so, is it specifically their competitive orientation that drives these differences? This paper uses survey data to observe differences in attitudes, decisions, leadership, and strategy between athletes and non-athletes. This paper also implements an experiment, which randomly assigns half of the participants to be primed by recalling a competitive situation to test whether differences in behavior between athletes and non-athletes can be attributed to a competitive mindset. The survey undertaken for this purpose received 100 responses. In this research, the role of a competitive mindset was examined, which is frequently developed through sports, plays in entrepreneurial attitudes, priorities, and strategies. This paper tests if athletes and non-athletes make different decisions in the face of entrepreneurial challenges. It also examines whether any of those differences can be attributed to the competitive orientation of people with athletic experience.

\section{Introduction}

"Sport is so much like business. It's all about strategy. And it's all about learning from losing. It's all about setting goals. the skills I developed in tennis were the same skills that made me a successful entrepreneur" -Venus Williams

Venus Williams is best known for her dominance on the tennis court, but she is the CEO of two highly successful companies. As she points out, many of the attitudes and skills people develop through competing in sports parallel the attributes thought to make a successful entrepreneur. People who grow up competing in athletics often develop exceptional leadership, teamwork, and problem solving skills. Challenging practices and constant feedback push them to become coachable and develop a strong work ethic. Regular games, meets, and tournaments push them to gain comfortability with, and often fondness of, competition. Through competition, athletes are pushed to think strategically, act and pivot quickly, and improve their game to rise above each new opponent.

It follows logically that one having athletic experience, may be naturally equipped for the challenges of entrepreneurship. Dino Ruta and Paolo Guenzi, researchers who have studied sports and entrepreneurship, said that sports leadership is used as a powerful analogy for analysing business leaders' actions such as motivation, teamwork and human resource management. Coaches are often seen as role models for company managers. Sports trainers and managers have many things in common.

While winning sports championships and receiving business awards fall on the path to greatness, extraordinary athletes and entrepreneurs realize the mark they want to leave on the world is bigger than that. They focus on creating a legacy, something that will survive much longer than them (Sahil Vora). Notably, while people without athletic experience can also be successful entrepreneurs, athletes may have a natural ability to think strategically and 
overcome obstacles and they may find themselves comfortable in and motivated by intense market competition while others shy away.

This paper poses a few questions about the link between athletic experience and entrepreneurial behavior. Does athletic experience affect entrepreneurial attitudes, decisions, and, therefore, outcomes? If so, is it specifically their competitive orientation that drives these differences? This paper uses survey data to observe differences in attitudes, decisions, leadership, and strategy between athletes and non-athletes. This paper also implements an experiment, which randomly assigns half of the participants to be primed by recalling a competitive situation to test whether differences in behavior between athletes and non-athletes can be attributed to a competitive mindset. The survey undertaken for this purpose received 100 responses.

In this research I also specifically examine the role that a competitive mindset, which is frequently developed through sports, plays in entrepreneurial attitudes, priorities, and strategies. This paper tests if athletes and non- athletes make different decisions in the face of entrepreneurial challenges. It also examines whether any of those differences can be attributed to the competitive orientation of people with athletic experience.

\section{Literature Review}

Participation in sports has been shown to have a wide variety of effects on the psychology and skill sets of adolescents. Evidence suggests that participation in sports provides a greater sense of agency in individuals (Pierce, et al). Increased awareness, self-expectations and self-confidence, helping individuals develop leadership skills. Sports strengthen their sense of identity, purpose and well-being (O'neill, Pierce, et al). Community sport participation is a form of leisure time for children and adolescents, in an effort to not only improve physical health in relation to such matters as the obesity crisis, but also to enhance psychological and social health outcomes. Developing a high perceived sports competence through object control skill development in childhood is important for both boys and girls in determining adolescent physical activity participation and fitness (Lisa M Barnett, Philip J Morgan, Eric van Beurden \& John R Beard). Through learning moves, skills, and tactics athletes learn to harness an intrinsic sense of competitiveness (Davids et al., 2016).

Participation in athletics can also promote a growth mindset. A growth mindset is a belief that one can become significantly more skilled or more intelligent through effort, practice and education. In contrast, a fixed mindset is a belief that human attributes are fixed and permanent qualities (Dweck, 2012).Furthermore, research has shown that people with a growth mindset tend to face challenges as an opportunity for learning, while people with a fixed mindset tend to avoid challenges.

According to the literature, the word "entrepreneur" appeared first in 1253. Later, the word slowly got its prominence in 1500 and 1600 and at present it is identified as "enterprise leader" (Fillon, 2011). Schumpeter defined Entrepreneurs as those "who exploit through their technical or organizational innovation" (Eroglu \& Picak, 2011). Much research has attempted to understand what makes up a successful entrepreneur. One report states twelve essential characteristics of a successful entrepreneur. They are confident, system-oriented, dedicated, grateful, optimistic, gregarious, and passionate about learning. They work well in teams, have strong communication skills, lead by example, and have a strong sense of ownership, are able to communicate, are passionate about learning, and are a team player (Action Coaching, 2015). Another report describes a similar set of qualities that make up a successful entrepreneur. They are passionate, visionary, energetic, driven, self-starting, decisive, calculated, risk-taking, resilient, determined, focused, result-oriented, persuasive, and lucky. They are strong leaders and strong multitaskers (Qualities of an Entrepreneur, 2015).

Entrepreneurs benefit from strong leadership skills, self-efficacy (Open Prospects), and self-awareness, which are qualities that can be successfully built through participation in athletics. This paper examines the relationship between sports experience and entrepreneurial attitudes, priorities, and strategies. 


\section{Methodology}

It is expected that people with past experience in sports tend to approach entrepreneurial decisions differently in terms of their competitive mindset, leadership abilities, and strategic thinking. It is expected that this tendency is driven by the competitive nature of athletics, which prepares individuals to take on competitors' firms when placed in a business/entrepreneurial setup.

This prediction is tested by administering a survey about entrepreneurial decision making. An analysis is conducted on the difference in responses between people with experience in competitive athletics and people without that experience. To test one mechanism, that these particular differences are driven by exposure to competition, a randomized experiment is run in which some participants are told to recall a competitive situation they have been in and describe the outcome. The others are in a control group and do not complete this exercise.

It is expected that athletes would focus more on gaining advantage over the competitor firms rather than the internal dynamics of the firm and satisfying customer needs. This is expected because an athlete is continuously exposed to competition which enables them to have the mindset to keep improving which can be termed as a competitive mindset. A specific examination is done on the role that a competitive mindset, which is frequently developed through sports, plays in entrepreneurial attitudes, priorities, and strategies.

The survey also tests the type of decisions an athlete would make when placed in crisis situations in an organisation such as labour turnover and unmotivated employees. It determines the priorities that athletes would have in an entrepreneurial situation when compared to non-athletes, such as becoming the leader in the respective industry, or making short term profits and satisfying customer needs.It is expected that athletes would choose short term profits because of the consistency skill developed by competing. The survey tests the difference in the level of consistency an athlete and non-athlete possess.

Student athletes are said to have more of a competitive mindset when compared to regular students, who are said to have a comparatively fixed mindset. The term comparatively is used here because students often do have a certain level of competitive mindset because of their education at schools. They often compete against each other in terms of grades, assignments etc. which automatically pushes them to perform better leading to them developing a sense of dedication and willingness to work hard. But an athlete competes in school with their classmates along with competition in their sport, leading to them having a strong competitive mindset. A regular student's goals are to perform well in school. There is a benchmark and if a student crosses that, they pass. But, an athlete always strives to win in any tournament they participate in. If they don't, they lose. This leads to them concentrating on their competition in a sport, more than they do in school.

In the survey that was registered, it is tested whether an athlete would enter into an industry they are passionate about, or an industry which has the highest profit margin. It is expected that athletes want to enter into an industry with high profit margins because of winning. Athletes always strive to climb up the ranking charts, and hence may want to win in an industry by being on the top with the highest profit margin. A test is conducted on whether an athlete would turn a company into a public limited company when given a chance or remain as a private limited company with consistent profits. The prediction is that an athlete would keep the company as a private limited company because of the skill of consistency they may develop through playing a sport competitively. The goal of an athlete is generally to be on the top of the ranking charts but also work towards consistent results.

A detailed analysis is made on what an athlete would focus on when placed in a hypothetical situation in which their business is facing a loss. The prediction is that athletes would be more likely to focus on gaining advantage over the competition rather than establishing leadership or understanding the venture's financial position.

Through the registered survey a test is conducted on what respondents think is the most important attribute of becoming a successful entrepreneur. This paper also analysed how the respondents would react to a situation in which there is high levels of employee demotivation in the organisation. The prediction is that athletes who played a team sport would be more likely to pick the option of involving the employees in the decision-making process rather than increasing pay for the employees. This is the prediction because an individual who has played a team sport must 
have learned the skill of team cohesion and taking into consideration the opinions and perspectives of people in the team.

A case study is conducted to test how the respondents would react when there is new competition in the market, stealing the market share from the business. The respondents were given the option of either partnering with the competition and letting everyone succeed or putting all their resources into innovating a product to regain their market share. The prediction is that the respondents who were primed into a competitive situation choose to put in all their resources into innovating a product to regain their market share. Another prediction is that athletes would choose to put in all their resources into innovating a new product.

Next, a test for consistency is conducted. Respondents were asked if they would rather become the market leader who is just breaking even or not take on the market leader role but make consistent profits. The prediction is that athletes would want to make consistent profits rather than be the market leader who is just breaking even. This is the prediction because in general athletes strive to be consistent with their performance, considering they are exposed to a lot of pressure and competition on a daily basis.

The next test analyses what the respondents think is the most accurate definition of leadership. The expectation is that athletes who play team sports consider leadership to be the ability to encourage employees to work efficiently rather than exerting power over the employees in the organisation. This is the prediction because, as mentioned earlier, athletes who play team sports are expected to have developed better team working abilities than non athletes. Through the survey it is tested whether respondents prefer adhocracy in an organisation of hierarchy. The expectation is to see that athletes would prefer adhocracy. As mentioned earlier, athletes are expected to always be quick on their feet and strive to climb up the ranking charts before their competitors. Adhocracy allows organizations to operate in a more flexible manner. It offers a sharp contrast to more formal styles of decision-making. This flexibility can work well in fast-changing industries where organizations that can identify and act on new opportunities the fastest have a competitive advantage (Kenton, Will).

\section{Results}

First, an analysis is made on participants' hypothetical approach to a situation in which they are an entrepreneur and their business is losing money. It is observed whether participants tend to focus externally on the competition and gaining advantage or tend to focus internally on improving employee motivation or perfecting their business practices, including marketing and branding. In line with expectations, people with sports experience were $18 \%$ more likely ( $\mathrm{p}=0.0892$ ) to choose to focus externally on the competition. However,there is no evidence that this effect is driven specifically by competitiveness, as there is no effect of the competitive priming treatment. In this analysis, I also control for gender, team vs. individual sport experience, and entrepreneurial experience.

Table 1. Respondents Priorities:

\begin{tabular}{|l|l|l|l|l|}
\hline & Estimate & Std. error & T value & $\operatorname{Pr}(>\mathrm{I} t \mathrm{I})$ \\
\hline (intercept) & $6.319 \mathrm{e}-01$ & $1.119 \mathrm{e}-01$ & 5.647 & $2.54 \mathrm{e}-07$ \\
\hline Treatment & $-9.465 \mathrm{e}-05$ & $1.137 \mathrm{e}-01$ & -0.001 & 0.9993 \\
\hline sport_experience & $1.885 \mathrm{e}-01$ & $1.095 \mathrm{e}-01$ & 1.721 & 0.0892 \\
\hline gender & $-1.680 \mathrm{e}-01$ & $1.039 \mathrm{e}-01$ & -1.618 & 0.1098 \\
\hline Entrepreneurial experience & $4.1753-02$ & $1.079 \mathrm{e}-01$ & 0.387 & 0.6999 \\
\hline
\end{tabular}


Next, an analysis is done on participants' hypothetical approach to a situation in which their business is facing a loss. It is observed whether participants tend to focus on gaining advantage over the competition, establishing strong leadership, or understanding their venture's financial potential. In line with expectations, people with sports experience were $20.8 \%$ more likely $(\mathrm{p}=0.0326)$ to choose to prioritize gaining advantage over the competition. However, no evidence is seen that this effect is driven specifically by competitiveness, as there is no effect of the competitive priming treatment. In this analysis, I also control for gender, team vs. individual sport experience, age, and entrepreneurial experience. The above response supports the prediction claiming athletes are more likely to have a competitive mindset.

Table 2. Respondents focus:

\begin{tabular}{|l|l|l|l|l|}
\hline & Estimate & Std. error & T value & Pr (>I I I) \\
\hline (intercept) & 0.06427 & 0.09767 & 0.658 & 0.5125 \\
\hline Treatment & -0.02740 & 0.09926 & -0.276 & 0.7833 \\
\hline sport_experience & 0.20790 & 0.09557 & 2.175 & 0.0326 \\
\hline gender & -0.05895 & 0.09067 & -0.650 & 0.5175 \\
\hline Entrepreneurial experience & 0.05200 & 0.09417 & 0.552 & 0.5824 \\
\hline
\end{tabular}

Next, an analysis is done on what the respondents think is the most important attribute to being a successful entrepreneur. No significant difference is observed between athletes and non-athletes, nor do I see an effect of the competitive priming treatment. This goes against the prediction that athletes would consider risk taking ability as the most important attribute. However, it could be seen that male respondents are $19 \%$ more likely $(p=0.0822)$ to choose leadership and risk-taking abilities as the most important attribute to being a successful attribute.

Table 3. Most important attribute of a successful entrepreneur:

\begin{tabular}{|l|l|l|l|l|}
\hline & Estimate & Std. error & T value & $\operatorname{Pr}(>\mathrm{I} \mathrm{t} \mathrm{I})$ \\
\hline (intercept) & 0.61624 & 0.11668 & 5.282 & $1.13 \mathrm{e}-06$ \\
\hline Treatment & 0.11560 & 0.11858 & 0.975 & 0.3326 \\
\hline sport_experience & -0.01627 & 0.11416 & -0.142 & 0.8871 \\
\hline gender & 0.19069 & 0.10831 & 1.761 & 0.0822 \\
\hline Entrepreneurial experience & -0.06630 & 0.11250 & -0.589 & 0.5573 \\
\hline
\end{tabular}

When given the following case study "You are the CEO of ABC limited. Your company is the market leader and is making profits. It is in the growth stage of the business cycle and has no competition in the industry. New competitor has entered the market and is gaining recognition fast. What would you do in this situation" respondents who were primed to have a competitive mindset were $29 \%$ more likely to put all their resources into innovating their product so they regain their advantageous position, rather than trying to establish a relationship with the competitors and find a way for everyone to succeed in the market. This result is significant $(\mathrm{p}=0.00715)$. It also seems that male 
respondents are $16 \%$ less likely to put in all of their resources into innovating a new product to regain their advantageous position. This means female respondents were more likely to choose the innovation option rather than Trying to establish a relationship with the competitors and find a way for everyone to succeed in the market. This result is significant at the $\mathrm{p}<0.09779$ level.No evidence is seen on whether this effect is driven specifically by entrepreneurial or sport experience.

Table 4. Responses to case study:

\begin{tabular}{|l|l|l|l|l|}
\hline & Estimate & Std. error & T value & $\operatorname{Pr}(>\mathrm{I}$ t I $)$ \\
\hline (intercept) & 0.66261 & 0.10594 & 6.254 & $2.06 \mathrm{e}-08$ \\
\hline Treatment & 0.29702 & 0.10748 & 2.763 & 0.00715 \\
\hline sport_experience & 0.03263 & 0.10359 & 0.315 & 0.75365 \\
\hline gender & -0.16487 & 0.09837 & -1.676 & 0.09779 \\
\hline Entrepreneurial experience & 0.06396 & 0.10219 & 0.626 & 0.53343 \\
\hline
\end{tabular}

Next, an analysis is conducted on participants' responses when given a choice of being a market leader and just breaking even or their business is not the market leader but is making consistent profits. It was found that respondents with sports experience were $16 \%$ less likely $(\mathrm{p}=0.0281)$ to choose being a market leader who is just breaking even. However, there is no evidence that this effect is driven specifically by competitiveness, as there is no effect of the competitive priming treatment. This result is in line with expectations and it could mean that athletes prefer to be consistent performers rather than being at the top of the market without clear profits.

Table 5. Market leader or Consistent Performance:

\begin{tabular}{|l|l|l|l|l|}
\hline & Estimate & Std. error & T value & $\operatorname{Pr}(>\mathrm{I} \mathrm{t} \mathrm{I})$ \\
\hline (intercept) & 0.96692 & 0.06757 & 14.310 & $<2 \mathrm{e}-16$ \\
\hline Treatment & 0.08931 & 0.07755 & 1.152 & 0.2529 \\
\hline sport_experience & -0.16782 & 0.07504 & -2.236 & 0.0281 \\
\hline
\end{tabular}

When respondents were asked what their definition of leadership is out of the given options 'The ability to encourage employees to work efficiently' or 'The ability to exert power over employees and ensure they complete their work promptly' athletes who played a team sport were $7 \%$ less likely $(\mathrm{p}=0.189)$ to choose the ability to encourage employees to work efficiently. However, there is no evidence that this effect is driven specifically by competitiveness, as there is no effect of the competitive priming treatment. In this analysis, I also control for gender, age, and entrepreneurial experience. 
Table 6. Definition of leadership:

\begin{tabular}{|l|l|l|l|l|}
\hline & Estimate & Std. error & T value & Pr (>I t I) \\
\hline (intercept) & 0.90987 & 0.04722 & 19.270 & $<2 \mathrm{e}-16$ \\
\hline Treatment & 0.06108 & 0.04799 & 1.273 & 0.207 \\
\hline sport_experience & 0.02436 & 0.04620 & 0.527 & 0.600 \\
\hline gender & 0.06509 & 0.04383 & 1.485 & 0.142 \\
\hline Entrepreneurial experience & -0.01266 & 0.04553 & -0.278 & 0.782 \\
\hline
\end{tabular}

When respondents were asked how they would structure their organizations, athletes were $4 \%$ more likely to favor adhocracy, as opposed to hierarchy. This result is significant $(\mathrm{p}=0.02147)$. No evidence suggests that this effect is driven specifically by competitive orientation, as the competitive priming treatment had no effect on participants' answers. No significant difference in answers between people of different ages, genders, or levels of entrepreneurial experience could be observed.

Table 7. Adhocracy or Hierarchy:

\begin{tabular}{|l|l|l|l|l|}
\hline & Estimate & Std. error & T value & $\operatorname{Pr}(>\mathrm{It} \mathrm{I})$ \\
\hline (intercept) & 0.34730 & 0.10105 & 3.437 & 0.000936 \\
\hline Treatment & 0.06229 & 0.11597 & 0.537 & 0.592644 \\
\hline sport_experience & -0.05930 & 0.11222 & -0.528 & $(\mathrm{p}=0.02147)$ \\
\hline
\end{tabular}

\section{Discussion}

The first test for the respondents was a hypothetical situation in which the respondents were entrepreneurs and they were losing money. It was observed whether participants would focus more on the external factors like competition in the industry, or the internal factors such as employee motivation, marketing and branding etc. In line with expectations, It was found that respondents with sports experience were $18 \%$ more likely to choose to focus on competition rather than the internal factors in an organisation. This is in line with ] the prediction made that athletes have a more competitive mindset when compared to non athletes. Hence, they prioritize their competitors in the market when facing a loss. This was expected because athletes are faced with pressure and competition on a daily basis, as they have to keep trying to climb the ranking charts, overtaking their opponents, in order to succeed and get better opportunities. This quality plays an advantageous role in today's business environment with new competition coming into the market everyday. Everyone is striving to be on top and gain the majority of the market share. Hence, keeping an eye on the competition can be advantageous to an entrepreneur while running their business. In this analysis I also control for age, individual sports vs team sport experience, gender and entrepreneurial experience.

The next test was to see participants' hypothetical approach to a situation in which their business is facing a loss. The research looks at whether participants tend to focus on gaining advantage over the competition, establishing strong leadership or understanding their venture's financial potential. In line with lexpectations, people with sports experience were $20.8 \%$ more likely ( $\mathrm{p}=0.0326$ ) to choose to prioritize Gaining advantage over the competition. This 
means that athletes have a comparatively greater competitive mindset when compared to non athletes. But what do we really mean by this term? Mindset is defined as "an established set of attitudes held by someone," according to the New Oxford American Dictionary. Writer and entrepreneur Evan Carmichael said: "If there is something in common between the world's highly successful entrepreneurs , it is their winning mindsets." Research has shown that mindset needn't be "set". Stanford University psychologist, Carol Dweck, proposes that there are two different types of mindset: fixed mindset or a growth mindset. Successful businesses flourish under healthy competition (Eleza, 2021). They view competition as an opportunity, not an impediment. Competition is an essential part of the business landscape. In fact, a healthy competition challenges you to use the resources you have efficiently (Eleza, 2021). Competition encourages continuous innovation, pushes the entrepreneur to establish a better brand authority, could help the entrepreneur stroke unexpected partnerships, it could be an opportunity for mutual learning, it could help make a business turn to a customer oriented one, helps ride onto new trends in the market, and could also help an entrepreneur get new opportunities (Eleza, 2021).

The next test was done to test what respondents think is the most important attribute to being a successful entrepreneur.No evidence suggests that any effect is driven specifically by competitiveness, as there is no effect of the competitive priming treatment. However, Through the registered survey it was observed that male respondents are $19 \%$ more likely $(\mathrm{p}=0.0822)$ to choose leadership and risk-taking abilities as the most important attribute to being a successful attribute. This may play to an advantage for the entrepreneur as it improves productivity of the workforce, ability to succeed under pressure, emotional intelligence, charisma and seriousness in business operations, Growth and confidence in the team, listening and communication skills (Rapid Boost Marketing). Most important of all, entrepreneurial leaders are focused on developing others around them and create a sense of urgency within the organisation and a mission worth achieving. They set goals that stretch people's abilities, develop a spirit of teamwork and build confidence (Small Business Charter). However there are disadvantages to prioritizing leadership in an organisation. Autocratic leadership is rarely effective. Since group members are not the part of decision making, this may lead to decrease in employee morale. Chances of lack of trust between leader and group can be more. Bureaucratic leadership is inflexible due to structured patterns. This type of leadership does not offer creativity to the employee. Organisations following this type of leadership barely adopt any changes. In transformational leadership leaders sometimes become insensitive towards their employees. They focus more on the target rather on the employee's creativity and encouragement. In laissez faire leadership, if the member of the group is not capable, the probability of getting an inappropriate result increases. In strategic leadership, forecasting may lead to inaccurate results. Flexibility is difficult due to structured plans and strategies (Plopdo).

The next test was done to test a hypothetical situation in which a business is the market leader and competition enters the market, stealing the market share. The respondents had the option of either partnering up with the competition, or putting all their resources into innovating a new product to regain market share. Respondents who were primed to have a competitive mindset were $29 \%$ more likely to Put all their resources into innovating their product so they regain their advantageous position, rather than Trying to establish a relationship with the competitors and find a way for everyone to succeed in the market. This result is significant at the $\mathrm{p}=0.00715$ level. This result is in line with my prediction that a competitive mindset might drive one to choose the route of innovating a product to regain the advantageous position rather than collaborating with the competition and letting everyone succeed. However, it is interesting to note that this result was not driven by athletic experience of the respondents. This may imply that athletes may not always have a competitive mindset. This might indicate that a person with a competitive mindset would like to do things on his own and succeed rather than succeed by joining hands with the competition. It also seems that male respondents are $16 \%$ less likely to put in all of their resources into innovating a new product to regain their advantageous position. This means female respondents were more likely to choose the innovation option rather than trying to establish a relationship with the competitors and find a way for everyone to succeed in the market. This result is significant at the $\mathrm{p}<0.09779$ level. 
The next test was done to analyse participants' responses when given a choice of being a market leader and just breaking even or, their business is not the market leader but is making consistent profits. It was found that respondents with sports experience were $16 \%$ less likely $(\mathrm{p}=0.0281)$ to choose being a market leader who is just breaking even. This result could mean that athletes would like to be more consistent with their performance than respondents with no sports experience. But this result contradicts the prediction of athletes having a growth mindset. Consistency allows for measurement and accountability. It establishes the businesses reputation, maintains the organisation's messages and also makes the business relevant.

This may play as an advantage to businesses in the 21 st century as there are many firms entering the market on a daily basis and consistent performance is required in order to maintain customer loyalty and brand awareness. Being consistent helps people know what to expect from the business. It encourages businesses to deliver high quality and more efficient results. It can also help the business internally as it helps identify the gaps in the organisation and enables the business to look into methods that can aid in improving the efficiency of the business.

When respondents were asked what their definition of leadership is out of the given options 'The ability to encourage employees to work efficiently' or 'The ability to exert power over employees and ensure they complete their work promptly'. Athletes who played a team sport were $7 \%$ less likely $(p=0.189)$ to choose the ability to encourage employees to work efficiently.this is against my prediction as I thought athletes who played team sports would more likely understand the needs of the employees better and encourage them to work efficiently, but this result is not as significant as the $\mathrm{p}$ value is not as low. This may be an inaccurate result.

When respondents were asked how they would structure their organizations, athletes were $4 \%$ more likely to favor adhocracy, as opposed to hierarchy. This result is significant ( $\mathrm{p}=0.02147)$. I do not see evidence that this effect is driven specifically by competitive orientation, as the competitive priming treatment had no effect on participants' answers. Adhocracy allows organizations to operate in a more flexible manner. It offers a sharp contrast to more formal styles of decision-making. This flexibility can work well in fast-changing industries where organizations that can identify and act on new opportunities the fastest have a competitive advantage (Kenton, Will).

When respondents were asked which industry they would want to enter into when given the options 'industry that I am passionate about' or 'industry that has the highest profit margins'. The earlier prediction was that athletes would want to enter into an industry that has the highest profit margin because of "winning". But against my expectation no significant difference was seen between athletes and non athletes.I do not see evidence that this effect is driven specifically by competitiveness, as there is no effect of the competitive priming treatment. In this analysis, I also control for gender, team vs. individual sport experience, and entrepreneurial experience.

\section{Conclusion}

Overall, having athletic experience can influence the decisions one makes in an entrepreneurial situation, as athletes tend to have more of a competitive mindset when compared to a non-athlete. According to my results, people having sports experience do have a competitive mindset based on their priorities in an entrepreneurial situation. I also found gender differences in the analysis of the survey. Male respondents were more likely to pick risk taking abilities as the most important attribute of being a successful entrepreneur when compared to female respondents. I found that athletes were aiming to be more consistent with their performance when compared to people without any sports experience. This was seen when athletes were asked if they would want to be the market leader or a middle sized firm making consistent profits. In the analysis, I found that athletes were seen to favor being a middle sized firm with consistent profits. Athletes were seen to favor adhocracy as the structure for an organisation over hierarchy. In the 21 st century adhocracy is being given more importance as employee motivation is becoming a major concern in organisations. From the results of the survey, I found that people with experience in team sports were less likely to choose the ability to encourage workers to complete their tasks efficiently as the definition of leadership. By analysing the survey results, I was able to see a difference in the thinking process of athletes and non athletes when it comes to dealing with entrepreneurial situations. Being an athlete could make one a better entrepreneur, but athletes' decisions may not 
always be the way to go in an entrepreneurial situation as they are driven by different factors in different situations. By the results of this paper, it could be concluded that there is a difference in the decisions a person makes based on if they have experience playing a sport or they do not have that experience. This difference in decision making could be based on different factors such as competitiveness, leadership abilities , or strategic thinking.

\section{References}

Lisa Michele Barnett, Philip J Morgan, Eric van Beurden, John R Beard's ,International Journal of Behavioral Nutrition and Physical Activity 5(1):40DOI:10.1186/1479-5868-5-40(September

2008).https://www.researchgate.net/publication/23156000_Perceived_sports_competence_mediates_the_relationshi p_between_childhood_motor_skill_proficiency_and_adolescent_physical_activity_and_fitness_A_longitudinal_asse ssment.

Aziz, A. A. A., \& Rowland, S. (2018, October 19). The entrepreneurship skills that biotechnology graduates need: Findings from entrepreneurial employees in a developing economy. Entrepreneurship Education. https://link.springer.com/article/10.1007/s41959-018-0006-7.

Jyothi Shreedhar .Care when you dare: A selective study. (n.d.). https://www.ijariit.com/manuscripts/v3i1/V3I11253.pdf.

Guenzi, D. R. and P. (2013, November 25). What can business leaders learn from sports leadership? Strategic HR Review. https://www.emerald.com/insight/content/doi/10.1108/SHR-07-2013-0072/full/html.

Iftime, C. (n.d.). Sport management principles and application hoye et all. Academia.edu. https://www.academia.edu/16355896/Sport_Management_Principles_and_Application_Hoye_et_all.

The importance of self-confidence for entrepreneurs \& steps to increase yours. Open Prospects. (2020, September 30). https://www.openprospects.com/importance-self-confidence-entrepreneurs/.

Kenton, W. (2021, June 26). Adhocracy. Investopedia. https://www.investopedia.com/terms/a/adhocracy.asp. Lze, A. N. (n.d.). Department of education teaching students who are gifted and talented a handbook for Teachers 2013. Academia.edu.

https://www.academia.edu/40097642/Department_of_Education_TEACHING_STUDENTS_WHO_ARE_GIFTED _AND_TALENTED_A_Handbook_for_Teachers_2013.

Neck, C. (2015, December 15). Your mindset can be a competitive advantage in business, life. The Arizona Republic. https://www.azcentral.com/story/money/business/entrepreneurs/2015/12/14/your-mindset-cancompetitive-advantage-business-life/77106944/.

Paul Downward, A. D. (2009, June 4). The economics of SPORTS Participation: Evidence 4.1 introduction: Pau. Taylor \& Francis. https://www.taylorfrancis.com/chapters/mono/10.4324/9780080942087-13/economics-sportsparticipation-evidence-4-1-introduction-paul-downward-alistair-dawson-trudo-dejonghe.

Premratan, A. (2020, March 13). Different types of leadership and their advantages and disadvantages. PloPdo. https://plopdo.com/2018/12/19/different-types-of-leadership-and-their-advantages-and-disadvantages/. raquelmsnksa1. (n.d.). https://raquelmsnksa1.wordpress.com/. Technology consulting, software development, mobile apps, digital marketing, advertising \& lead Generation Partner. Digital Marketing, Advertising, SEO, Social Media, Website Design \& Online Marketing. (2021, June 23). https://rapidboostmarketing.com/.

Vora, S. (2019, March 27). Why sportsmen make good entrepreneurs. Entrepreneur. https://www.entrepreneur.com/article/330438.

Vora, S. (2019, March 27). Why sportsmen make good entrepreneurs. Entrepreneur. https://www.entrepreneur.com/article/330438. 